\title{
Eyelid Xanthoma
}

National Cancer Institute

\section{Source}

National Cancer Institute. Eyelid Xanthoma. NCI Thesaurus. Code C3651.

A condition characterized by the formation of fatty deposits under the skin in the area of the eyelids. These well-demarcated growths, more common in women than men and sometimes hereditary, may indicate elevated cholesterol levels in the blood or the fatty degeneration of the superficial fibers of the orbicularis muscle. 